\title{
NEUTRALIZANDO CONHECIMENTO: como jornalistas lidam com experts
}

\author{
Liriam Sponholz
}

Resumo: Jornalistas são um dos alvos preferidos de políticos, mas também de think tanks e seus experts, para exercer influência sobre os acontecimentos políticos e econômicos de uma sociedade. Até que ponto esses profissionais estão preparados para reagir produtiva e ao mesmo tempo criticamente a essas iniciativas? Nesta pesquisa qualitativa com repórteres de jornais brasileiros de circulação nacional e regional, levantaram-se informações sobre como os entrevistados escolhem experts na cobertura de temas polêmicos, quais informaçőes esperam dessas fontes e como retratam esse tipo de informante. Os resultados mostram que os jornalistas entrevistados procurariam, rotineiramente, os mesmos experts e não confrontariam as informações obtidas com uma segunda fonte.

Palavras-chave: think tanks; experts; conhecimento; jornalismo.

No final de 2005, uma notícia alcança as homepages da $\mathrm{BBC}$ Brasil e edições online dos jornais do país: Brasil ameaça pesquisa sobre AIDS (BBC, 2005). O texto trata de um estudo crítico realizado pelo American Enterprise Institute (AEI) sobre o Programa de Combate de Doenças Sexualmente Transmissíveis e AIDS do Ministério de Saúde brasileiro, reconhecido e premiado internacionalmente ${ }^{1}$. Os autores do estudo, Richard Tren e Roger Bate, criticam, sobretudo, a forma como o governo brasileiro lida

\footnotetext{
* Jornalista, Mestre em História pela Universidade Federal do Paraná (UFPR) e doutora em Comunicação pela Universidade de Leipzig (Alemanha).E-mail: l_sponholz@hotmail. com
}

Artigo recebido em 26 abr. 2008 e aprovado em 24 jun. 2008. 
com as patentes dos medicamentos utilizados no tratamento da doença e a pressão exercida para que o preço destes seja reduzido. No texto, não constam informaçőes nem sobre o método utilizado, nem sobre os resultados empíricos do estudo. Sobre os autores, a única informação encontrada no texto refere-se a sua ligação com o AEI, "um centro de estudos financiado por doações de indivíduos e empresas".

Esse "centro de estudos" é identificado claramente como conservador no cenário político norte-americano (Soley, 1992, 1998; Thunert, 2003). Think tanks conservadores trabalham com uma pauta relativamente fixa de temas, como the free market system (including low taxes, privatisation and deregulation), limited government, individual liberties and values and/or strong religious expression, traditional family values and a strong defense (Thunert, 2003).

Por que essas informações sobre o AEI não foram mencionadas em uma notícia sobre um estudo deste think tank que os próprios jornalistas e as empresas para as quais trabalham classificaram como importante? A forma como jornalistas lidam com experts pode fornecer indícios para uma resposta.

O problema será analisado neste artigo a partir dos resultados de uma pesquisa qualitativa com repórteres de jornais nacionais e regionais no Brasil. Por meio deste estudo, foi possível observar, por meio de uma simulação, como esses jornalistas lidariam com experts na cobertura de temas polêmicos ${ }^{2}$.

$\mathrm{Na}$ primeira parte do artigo, apresentam-se o referencial teórico utilizado e um resumo das pesquisas mais recentes sobre o tema. Em seguida, descreve-se o método utilizado, seguindo-se uma apresentação dos resultados obtidos. No final do texto, discutem-se as conseqüências políticas e epistemológicas dos modos como os jornalistas entrevistados lidam com experts, bem como propostas para superar tais problemas. 


\section{O que é um expert?}

A definição e a função deste tipo de informante podem ser analisadas tanto do ponto de vista sociológico quanto jornalístico. Na perspectiva sociológica, os experts recebem um determinado papel social, que pressupõe uma competência específica, na maior parte dos casos, mediante o exercício de uma profissão.

O saber do expert se distingue do conhecimento geral por ser detalhado e por uma grande quantidade de fatos, mas também pela capacidade de estabelecer relações entre fatores e analisar as possíveis conseqüências de determinadas ações. Dessa maneira, o expert se diferencia tanto do leigo, que não tem nem o saber especializado, nem a legitimação profissional do primeiro, quanto do especialista, que pode até ter o conhecimento específico, mas não dispõe da qualificação profissional de um expert (Schneckener, 2005, p. 5).

O conceito de expert gera o de leigo através de um determinado processo social e da conseqüente hierarquização dos saberes. Esse processo social é marcado por um aumento da complexidade em sociedades modernas, que exige uma divisão do trabalho (inclusive cognitiva) cada vez mais detalhada (Sprondel, 1979). Por um lado, surge uma série de novos problemas nessas sociedades resultantes de uma mudança nas estruturas sociais, os quais o homem comum não tem mais condições de resolver ou cuja solução o sobrecarrega.

Por outro lado, nessas sociedades, há uma tendência de "leigalizar" o saber não profissional e de profissionalizar áreas nas quais, antes, o conhecimento geral era visto como suficiente, como a educação dos filhos. A "consciência moderna" (idem, ibidem, p. 140) caracteriza-se pelo aumento da discrepância entre o saber individual e o produzido e colocado à disposição para a sociedade. Conseqüentemente, a abrangência do conhecimento individual encolhe e a dependência do conhecimento específico para a resolução 
de problemas (inclusive cotidianos) cresce (Bohman, 2000, p. 51; Sprondel, 1979, p. 141).

O processo de "leigalização" conduz a uma hierarquização do conhecimento, por meio da qual se nega a legitimação do saber produzido de maneira assistemática ou não profissional (Hesse, 1998, p. 43). Nesse processo, o pedagogo, por exemplo, recebe uma competência socialmente reconhecida enquanto esta é tomada da experiência dos pais (Sprondel, 1979, p. 142).

Em algumas áreas, como no caso da política, esse processo é restringido normativamente. Embora se reconheça que experts possam contribuir para a solução de problemas nessa área, as decisões em sociedades democráticas devem ser tomadas pelo público em geral (Bohman, 2000, p. 50; Sprondel, 1979).

Outra exceção ao poder gerado por essa hierarquização de saberes pode ser observada em situações de risco. Boyce (2006, p. 898) mostra, em seu levantamento empírico da cobertura jornalística sobre uma possível correlação entre autismo e a vacina contra rubéola, sarampo e caxumba na Grã-Bretanha, que, nesse caso, experts tiveram que se posicionar perante a experiência cotidiana e a opinião de pais (alguns deles de crianças autistas). Com as opiniões de experts de um lado e pais do outro lado, os jornalistas tentaram preservar o princípio do equilíbrio (balance), o que aponta para o tratamento dos dois tipos de saberes com uma certa igualdade de status, nesse caso.

\section{O ponto de vista jornalístico}

O papel do expert na produção jornalística envolve três componentes, pelo menos: o papel do jornalismo na produção e distribuição do conhecimento, a exigência da qualidade comunicativa advinda do primeiro e as rotinas produtivas. 
O mesmo processo de aumento da complexidade em sociedades modernas que dá origem à expertise encarrega o jornalismo de uma tarefa especial. Esse tipo de atividade midiática deve exercer uma função de orientação social, concretizada no fornecimento de informações que permitam ao receptor "localizar-se" em um mundo cada vez mais complexo (Park, 1967).

Como Meditsch (1992, p. 30) explica, “um sujeito na Idade Média, que morasse num povoado ou numa vila, tinha conhecimento de suas relações diretas. Via o mundo mudando na sua imediaticidade, na sua manifestação [...] superficial, fenomênica. Ele via o mundo mudando à sua volta". Hoje em dia, o mundo atingiu tal complexidade, que não é mais possível estabelecer uma relação direta com ele. É nesse contexto que se insere a função de orientação social. Para exercê-la, jornalistas também têm que produzir conhecimento a partir da observação do seu meio ambiente, de informações obtidas por intermédio de investigação.

Tanto cientistas quanto jornalistas são mediadores entre a realidade e o seu público. Do ponto de vista epistemológico, a principal diferença entre ambos consiste nas diferentes formas de acesso à realidade. Genro Filho (1988, p. 64) ocupou-se com essa questão e sistematizou os diferentes tipos de conhecimento em três categorias: singular, particular e universal. Tudo que existe pode ser classificado em uma dessas categorias. Por exemplo, Pedro Silva pertence como tal à categoria singular. Como motorista de caminhão, ele pertence à categoria particular e, como ser humano, à categoria universal. Essa classificação não deve ser vista de maneira radical, já que Pedro pode ser parte de todas elas, por motivos diferentes.

O jornalismo ganha conhecimento sobre o mundo mediante o singular, enquanto a ciência se concentra no que há de universal. Ou seja, a ciência só se interessa por Pedro como ser humano ou como motorista de caminhão (isto é, como um dos pertencentes a 
esse grupo), mas não como indivíduo. Para o jornalismo, o mais importante é exatamente o que é menos universal.

Se Pedro sofrer um acidente com o seu caminhão em uma rodovia, o jornalismo vai se interessar como Pedro Silva, motorista de caminhão, 35 anos, pai de dois filhos, com uma jornada de trabalho de 16 horas por dia, se acidentou na rodovia BR-X, que se encontra em estado precário e não sofre reparações desde 1985. Para a ciência, esse acontecimento poderia ser importante, mas não como evento singular. O cientista pode escolher o acidente como tema dentro de um conjunto de acidentes com caminhões ou em um levantamento sobre a situação das rodovias. Isto é, a ciência só se interessa pelos aspectos particulares ou universais do caso. A sua exclusividade é ignorada. O jornalismo, porém, se importa exatamente com o que a ciência ignora.

De acordo com Genro Filho (ibidem, p. 65), a singularidade é a característica principal do jornalismo como tipo de conhecimento. É ela que impede que o jornalismo seja classificado como ciência. O jornalismo se concentra em casos, no que se sobressai, e não busca regularidades, como a ciência faz (idem, ibidem; Meditsch, 1992; Neuberger, 1996; Sponholz, 2007; Weischenberg, 1992). Por isso, o jornalista pode alcançar um grau mais alto de conhecimento relativo a um fato ou a um acontecimento do que o cientista. Por outro lado, essa característica inerente faz com que o jornalista tenha dificuldades em reconhecer conexões e analisar processos. Nesse contexto insere-se o expert e o seu saber. Ele deve encaixar a peça que o jornalista encontrou no quebra-cabeça.

Para o jornalista, o papel de mediador tem outra dimensão. Como ele exerce esse papel para um público que abrange desde o físico até o encanador, a apresentação do conhecimento produzido por esse profissional exige uma qualidade comunicativa maior do que a realizada pelo cientista (Lage, 1979; Meditsch, 1992; Park, 
1967). Conseqüentemente, a organização do conhecimento factual do jornalista, em um contexto maior, por intermédio do expert, exige, sobretudo, que isso ocorra de forma compreensível. Nesse caso, a relação entre o expert (principalmente o seu protótipo, o cientista) e o jornalista envolve não somente uma questão de quanto o jornalista e o seu público entendem sobre o assunto (public understanding of science), mas também um problema do cientista em compreender o público com o qual ele se comunica (scientific understanding of public) (Schnabel, 2003, p. 258).

O conhecimento das conexőes entre fatores e das possíveis conseqüências de determinadas ações ou acontecimentos pode caracterizar o expert do ponto de vista sociológico, mas não é suficiente do ponto de vista jornalístico. Essas características podem até ser ignoradas por jornalistas. Em levantamentos realizados com cientistas norte-americanos, Dunwoody e Scott (1982) não encontraram nenhuma relação entre a produtividade científica de um pesquisador e a freqüência com a qual ele foi entrevistado por jornalistas. Também já foi observado que cientistas são freqüentemente entrevistados sobre assuntos tangenciais ou não relacionados com o seu objeto de pesquisa (Dunwoody; Ryan, 1987).

Estudos empíricos apontam, ainda, para o fato de que o principal indicador para uma avaliação da expertise de um cientista por um jornalista é a sua vinculação institucional e a sua posição dentro da hierarquia de uma instituição, não a sua produção científica. Por isso, repórteres procuram contato com diretores de institutos, cientistas de universidades famosas e pessoas já conhecidas pelos meios de comunicação (Conrad, 1999, p. 291).

A adquirição sistemática de saber - como no caso do cientista - pode até mesmo ser considerada uma desvantagem por jornalistas, caso essa profissionalização colida com a expectativa do 
jornalista de que o expert forneça um quadro nítido da realidade. Jornalistas esperam que experts digam o que está acontecendo, o que, eventualmente, alguém do "mundo real" possa fazer melhor do que outra fonte da "torre de marfim" que tenha comprovadamente um conhecimento específico do assunto. Isso é o que mostra Steele (1995, p. 804) na sua pesquisa sobre a presença de experts nas notícias produzidas pelas emissoras de TV dos Estados Unidos durante a guerra no Golfo Pérsico:

Although a scholar claiming to be an expert on the Middle East would have to speak Arabic, be well-read in the literature of the field, and have completed a significant body of primary research, none of these criteria are important to television producers. Instead, journalists define expertise explicitly in terms of "real world" experience, access to and knowledge of the "players", and willingness to make predictions (p. 805).

A relevância de experts aumenta não somente com a complexidade dos temas a serem noticiados, mas também com a diversidade de opções de consumo midiático e com a concorrência entre os meios de comunicação. Todos esses fatores levam a uma necessidade ainda maior de orientação dos receptores, principalmente, em situações de risco (Thunert, 2003, p. 36). Esse cenário inflaciona a necessidade por previsões e por fontes com a competência socialmente reconhecida para fazê-las.

Do ponto de vista jornalístico, o expert é, portanto, em primeiro lugar, um tipo de fonte. Pode-se entender como fonte jornalística instituições ou pessoas que testemunham eventos de interesse público ou deles participam (Lage, 2001, p. 67) e são procuradas por jornalistas para a obtenção de informações ou sugestões de pauta (Gans, 1979). Fontes representam um fator decisivo no processo de produção jornalística. Notícias são a espinha dorsal desse processo e consistem não no que acontece, mas no que as fontes dizem que acontece (Sigal, 1986, p. 15). 
Experts podem ser utilizados como fontes: a) no jornalismo científico, para fornecer temas e informações secundárias a repórteres especializados; b) nas coberturas jornalísticas sobre situações de risco e/ou de conflito, como no caso do uso da energia nuclear ou de alimentos transgênicos, para fornecer informações secundárias a jornalistas não necessariamente especializados em ciência e c) na cobertura jornalística geral de temas complexos e/ou confusos, como no caso do noticiário econômico, para fornecer informações secundárias a jornalistas que, via de regra, não são especializados em ciência.

Fontes podem fornecer informações em dois níveis, o factual (respostas às perguntas o quê, quem, onde e quando) e o interpretativo (respostas às perguntas como e quando) (Haller, 2000, p. 61). No jornalismo científico, o expert fornece, sobretudo, informações no nível factual.

Nas coberturas jornalísticas não especializadas, a principal função desse tipo de fontes é dar sentido à notícia ou à reportagem mediante a organização dos fatos em um contexto e a previsão das conseqüências de um acontecimento (Lage, 2001). Nesse caso, criminosos e suas vítimas, representantes do governo, candidatos, líderes militares, terroristas e seus reféns e líderes de organizações de defesa de temas ou interesses específicos (Greenpeace, Attac, etc.) podem ser denominados de newsmakers, enquanto os experts fazem o papel de newsshapers (Soley, 1992, p. 2), ao fornecer informaçőes secundárias, de nível interpretativo.

Isso significa que experts fornecem informações que, ao contrário daquelas do nível factual, não podem ser averiguadas intersubjetivamente. Repórteres podem, por exemplo, averiguar se a informação de que cinco palestinos foram mortos durante um conflito ocorrido ontem com soldados israelenses é correta. No entanto, a intersubjetividade de uma averiguação mostra seus limites caso a questão sejam as causas do conflito entre Israel e palestinos. 
Outra diferença consiste no fato de que, via de regra, newsmakers são claramente posicionados dentro de uma cobertura sobre temas polêmicos e situações de conflitos como "um dos lados da questão”, o que não ocorre com experts.

Esses dois problemas-a impossibilidade de intersubjetividade, no caso das informações fornecidas pelo expert, e o fato de este não ser associado a um lado de uma polêmica - "oferecem a possibilidade de que jornalistas e meios de comunicação utilizem esse tipo de informante para divulgar opiniões como se fossem fatos (ideological or political bias) e, ainda por cima, com o status de 'fonte neutra'” (Rothman, 1992).

Rotinas de produção jornalísticas

Uma fonte jornalística, ou seja, o informante que jornalistas procuram, tem que ser capaz de se comunicar de forma compreensível e ser acessível aos repórteres (Dunwoody e Ryan, 1987, p. 25). Ou seja, o expert a ser entrevistado deve ter a capacidade comunicativa de dizer “o que está acontecendo”, ter uma vinculação institucional que lhe conceda credibilidade e adaptar-se às rotinas de produção jornalística. Steele (1995) denomina os fatores ligados às rotinas produtivas e às exigências específicas do meio de comunicação de operative bias.

Notícias são produzidas sob uma série de influências, as quais abrangem desde o jornalista e suas convicções até a forma de organização das redações e o sistema midiático em uma sociedade (Sousa, 2005). No entanto, na análise das intersecções entre a mídia e a política, as condições de produção jornalísticas não têm recebido a atenção necessária (Pedroso, 2005). Embora a análise do produto final possa fornecer elementos importantes sobre o relacionamento entre os dois campos, compreender o seu processo de produção é 
igualmente essencial, pois o que está escrito em uma notícia depende não somente de quem faz a notícia (a fonte), mas também do tempo e dos outros recursos de que o jornalista dispõe para procurá-la. Sob essa pressão, a acessibilidade e a disponibilidade da fonte em prestar informações fazem muita diferença.

A atividade de fontes, apoiadas por estratégias profissionais de relações públicas para garantir o seu acesso à mídia, representa um dos fatores de influência mais relevantes na produção de notícias. Os jornais recebem a maior parte da matéria-prima utilizada na produção de notícias na forma de press releases e entrevistas coletivas (Baerns, 1985; McNair, 1998; Sigal, 1973).

Dentro desse cenário, pode-se observar que uma grande parte dos experts presentes na mídia vem de think tanks (Steele, 1995; Dolny, 2002). Membros dessas organizações conseguem ter acesso à mídia por meio de diferentes estratégias, da apresentação da produção própria de estudos, como no exemplo citado no início deste artigo, até a produção de artigos para páginas de editoriais (Thunert, 2003, p. 237).

Esses tipos de iniciativa possibilitam aos think tanks influenciar a cobertura jornalística não só no caso dos temas iniciados por eles, mas também que seus representantes se estabeleçam como experts acessíveis, com uma alta qualidade comunicativa, que se colocam à disposição para comentar uma série de temas, inclusive os que não foram sugeridos por eles próprios. Dessa maneira, podem definir o enquadramento dos temas de outras fontes. Think tanks dão um grande valor à sua presença na mídia e investem tão maciçamente nessa tarefa (Soley, 1992; Thunert, 2003), que as suas atividades principais são vistas nas consultorias políticas e midiáticas.

A própria origem do conceito já aponta para uma orientação política clara e forte. Segundo Thunert (2003), o termo think tank surgiu durante a Segunda Guerra Mundial, nos Estados Unidos, 
como uma analogia a um lugar de onde as conversas não podem ser interceptadas (tank) e nos quais experts civis e militares traçam estratégias militares e planos de invasão (think).

Nos anos 60 e 70, o conceito passou a ser utilizado para denominar institutos de pesquisa intensivamente voltados para a prática. Hoje, tanto instituiçőes públicas e centros de pesquisas em universidades quanto aquelas com ligações políticas declaradas se utilizam do conceito. No entanto, o elemento constituinte central dos think tanks continua sendo a intenção de influenciar as políticas públicas (Thunert, 2003).

Embora estudos de ressonância midiática ainda não sejam tão comuns nas pesquisas de comunicação no Brasil, também se pode observar, por aqui, uma forte influência das relaçőes públicas em estudos de caso, nas imprensas local e regional, tanto em análises de output (como os de utilização de press releases de determinadas assessorias de imprensa) (Omellas, 2005; Resende, 2003), como também de input (nos quais a influência das assessorias de imprensa é observada a partir das redações) (Pereira, 2004, p. 98).

A influência de assessorias de imprensa e seus correlatos em publicações online não parece ser menor do que nas da mídia tradicional. Pereira (idem, ibidem) constatou que a maior parte das notícias divulgadas na versão online do Correio Braziliense vem de agências do governo (Agência Brasil, Agência Câmara e Agência Senado). O pesquisador observou um número maior de notícias dessas fontes (14\%) do que da própria redação do jornal (13\%).

Até que ponto os think tanks brasileiros se inserem nesse cenário, como ocorre nos Estados Unidos, é difícil dizer, já que a atuação de tais organizaçőes tem sido analisada quase exclusivamente pelas ciências sociais, que retratam o papel daquelas, sobretudo, na formulação de políticas. A influência dos think tanks sobre a mídia, por meio de sua adaptação às rotinas produtivas, ainda precisa 
ganhar relevância nos estudos de jornalismo no Brasil. O estudo apresentado aqui permite, entretanto, analisar o potencial existente para exercer influência sobre a imprensa dessa maneira (operative bias).

\section{Método}

A amostra desta pesquisa qualitativa abrange 20 repórteres das editorias de política (8), economia (5) e local (7) dos jornais O Estado de S. Paulo, Folha de S.Paulo, Jornal do Brasil, O Globo, Gazeta do Povo, Zero Hora, Correio Braziliense e O Estado de Minas. Eles foram escolhidos pelo número de reportagens publicadas no período de uma semana, entre maio e julho de 2004, e entrevistados por telefone.

Por esses critérios de seleção, foram escolhidos repórteres cuja produção é bastante significativa no cenário jornalístico do país. No grupo de entrevistados, há quatro setoristas ${ }^{3}$ de jornais de circulação nacional que trabalham em Brasília e respondem pela cobertura do Parlamento brasileiro (Congresso Nacional) e do Executivo (Palácio do Planalto), bem como dois setoristas de parlamentos estaduais. No caso da editoria de economia, há duas repórteres no grupo de entrevistados que trabalham em Brasília e cobrem os ministérios que atuam nessa área. No entanto, os nomes dos entrevistados não podem ser revelados, pois as entrevistas foram realizadas sob a condição de anonimato.

Para levantar os dados referentes aos métodos de investigação dos repórteres, estes receberam um texto antes da entrevista sobre um acontecimento fictício, que, no entanto, se assemelha à situação descrita em notícias reais recolhidas de jornais regionais e nacionais.

O acontecimento é apresentado nesses textos do ponto de vista de uma das fontes envolvidas. No final, o assessor de imprensa dessa 
fonte se coloca à disposição para prestar mais informaçőes. Com isso, procurou-se simular a situação em que jornalistas produzem uma notícia ou uma reportagem a partir de um press release.

Para cada editoria e para cada tipo de jornal (regional ou nacional) foram formuladas histórias diferentes. Com o objetivo de provocar os entrevistados a revelarem suas opiniőes, foram escolhidos temas polêmicos. Repórteres de política receberam um texto supostamente enviado pelo Ministério da Justiça sobre uma decisão tomada com relação à intervenção do Exército no combate à criminalidade nas cidades (para jornais nacionais) e outro sobre uma Comissão Parlamentar de Inquérito sobre o Movimento Sem Terra (para periódicos de circulação regional). Repórteres de economia receberam um texto cuja fonte seria uma empresa automobilística multinacional que pretende fechar suas fábricas no país (para jornais nacionais) e outro sobre um acordo entre trabalhadores e patrőes quanto ao fim de uma greve (para periódicos regionais). No caso da editoria local, todos os repórteres receberam um texto sobre uma nova iniciativa da polícia de combater a criminalidade em determinados bairros da cidade com uma campanha de desarmamento. Os repórteres entrevistados sabiam que as histórias eram fictícias.

Durante a entrevista, os entrevistados responderam como iriam produzir uma notícia ou uma reportagem a partir da história. Os resultados se baseiam, portanto, em como eles pensam que devem conduzir uma investigação jornalística, não em como eles de fato o fazem, embora se possa partir do pressuposto de que ambos os níveis se intersecionam.

Faz-se também necessário ressaltar que o foco da pesquisa não é o jornalista, mas, sim, o seu método de investigação. Por isso, os resultados não se baseiam, necessariamente, no número de jornalistas, mas no de fontes citadas por estes e no de suas hipóteses. Com relação às fontes, os repórteres escolhidos responderam quem 
iriam entrevistar para produzir uma notícia a partir da história enviada pela pesquisadora, como iriam entrar em contato com essa fonte e por que escolheriam tais informantes. Para levantar as hipóteses que os jornalistas iriam utilizar na sua investigação, eles contaram, durante a entrevista, o que iriam perguntar a cada uma das fontes.

Os textos das entrevistas foram degravados e submetidos a uma análise de conteúdo. A interpretação dos dados foi feita por meio de sua quantificação, o que significa que o método qualitativo de levantamento dos dados foi combinado com um método de interpretação quantitativo, para que eles pudessem ser agregados e classificados intersubjetivamente.

Utilizaram-se duas tipologias de fontes, uma estabelecida pela autora do estudo e outra levando-se em consideração o motivo pelo qual o jornalista escolheu a fonte. Na tipologia da pesquisa, codificaram-se como experts as fontes que possuem conhecimento específico (profissão) ou as que receberiam perguntas dos repórteres exigindo tal tipo de conhecimento, mas que não teriam poder de decisão no caso analisado nem seriam afetadas diretamente pelo acontecimento.

A segunda tipologia permite observar se o entrevistado escolheria a fonte por sua parcialidade (representar "um dos lados da questão”), por seu envolvimento no problema (como afetado), por sua competência na sua resolução (por exemplo, representantes de órgãos públicos), por seu poder de decisão (por exemplo, políticos), por sua neutralidade ou para a confirmação da tese adotada pelo repórter na sua investigação. A consideração dos resultados das duas tipologias é importante, pois uma fonte pode ser considerada como expert na tipologia da pesquisa, mas vista como parcial pelo jornalista entrevistado e vice-versa. Com relação ao contato com a fonte, este pode ser direto (no caso das fontes ouvidas rotineiramente), mediado pela assessoria de imprensa ou por terceiros (no caso de 
fontes ocasionalmente ouvidas, que precisam ser buscadas em listas telefônicas ou, por exemplo, no local do acidente).

As perguntas que os repórteres fariam às suas fontes podem se encontrar em um nível factual (o quê, quem, quando e onde) ou interpretativo (como e por quê). Tais questőes também contêm as hipóteses ou tentative beliefs que os jornalistas pretendem testar com a sua investigação, as quais são identificadas, no texto, por palavras como se, caso, provavelmente, entre outras, e podem ser descritivas, avaliativas ou prescritivas (Stocking e LaMarca, 1990). A oração "O prefeito não construiu nenhuma escola durante a sua gestão" é do tipo descritivo, enquanto "O prefeito é ruim" e "O prefeito deve renunciar" podem ser classificadas, respectivamente, como avaliativa e prescritiva. Somente hipóteses descritivas podem ser testadas intersubjetivamente.

Com referência aos experts, pressupõe-se que os entrevistados os escolheriam, sobretudo, por contato direto (Hipótese 1) e que as informaçőes fornecidas por eles não seriam averiguadas com uma segunda fonte (Hipótese 2).

\section{Resultados}

Experts representam 12\% de todas as fontes que os repórteres mencionaram (Gráfico 1). Se as fontes que, supostamente, iniciariam o contato com a imprensa forem excluídas do número total de informantes citados, o percentual de experts na amostra aumentará para 17\%. A maior parte deles (44\%) foi mencionada por repórteres de economia. Na editoria política, registrou-se o menor percentual (22\% dos experts citados) ${ }^{4}$. 


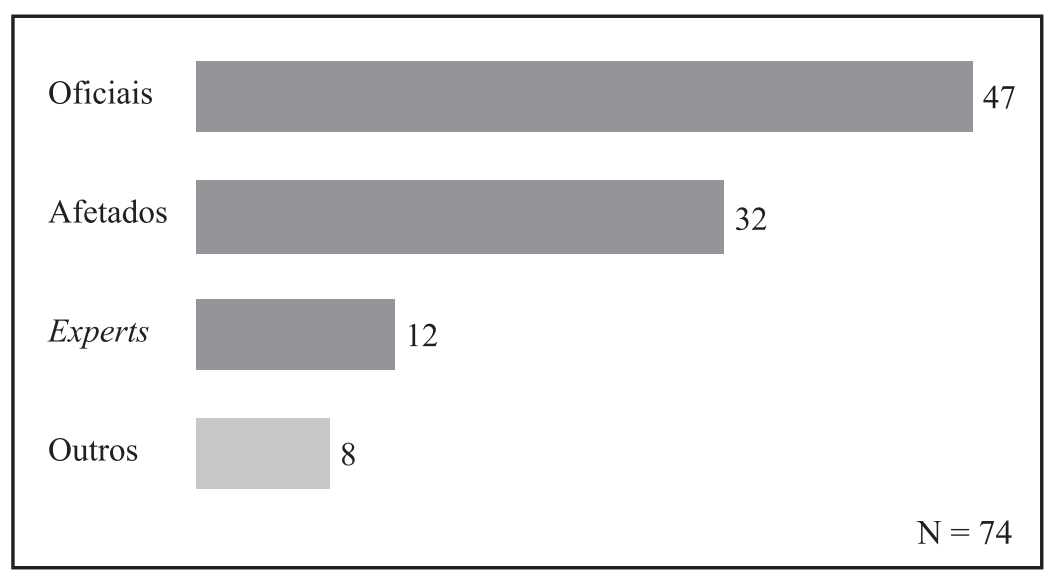

\section{Gráfico 1 - Tipos de fontes citadas pelos jornalistas (Número de fontes em \%).}

A maioria dos experts mencionados (56\%) seria alcançada por contato direto (Hipótese 1), ou seja, eles já constam nas cadernetas de telefone das redações (Tabela 1). Em comparação com outras fontes, esse índice é muito alto, já que até mesmo fontes oficiais seriam contatadas, principalmente, por meio de assessorias de imprensa, apesar do grande número de setoristas na amostra (seis dos 20 repórteres entrevistados). Os resultados mostram que esses repórteres procuram, rotineiramente, os mesmos experts.

Tabela 1- Como jornalistas entrariam em contato com as fontes citadas

\begin{tabular}{|c|c|c|c|c|}
\hline & Diretamente & $\begin{array}{c}\text { Por assessoria } \\
\text { de imprensa }\end{array}$ & $\begin{array}{c}\text { Por meio de } \\
\text { terceiros }\end{array}$ & $\begin{array}{c}\text { Não } \\
\text { respondeu }\end{array}$ \\
\hline Afetados & 12 & 17 & 71 & - \\
\hline Oficiais & 23 & 57 & 9 & 11 \\
\hline Experts & 56 & - & 33 & 11 \\
\hline Outros & 50 & & 17 & 33 \\
\hline
\end{tabular}

Cramer-V $=0,272 ; p=0,001 \quad \mathrm{~N}=74$ 
Analisando o número de experts citados por entrevista, verifica-se que um único jornalista iria entrevistar mais de um expert. Isso aponta para uma confirmação da segunda hipótese deste estudo, de que as informaçőes fornecidas por esse tipo de fonte não seriam confrontadas com uma segunda fonte. Ao mesmo tempo, a única fonte escolhida, por ser considerada neutra, é um expert ${ }^{5}$. Esse é o caso da repórter de economia de um jornal nacional, que recebeu a história “Indústria de automóveis XY pode fechar fábricas no Brasil”. De seu ponto de vista, o problema a ser investigado nessa pauta é a sustentabilidade de raciocínio do presidente da XY no Brasil: "Ele diz que as operações brasileiras foram responsáveis por um prejuízo considerável, que no Leste europeu a mão-de-obra é mais barata [...]. A idéia, aqui, é saber quais são os dados indicadores que levaram essa pessoa, o chefe da XY, a fazer essa avaliação”.

A investigação dessa jornalista consistiria, principalmente, em entrevistas com experts, dos quais ela espera obter tais dados. Para completar a sua matéria, ela deseja, por último, ouvir o representante do Ministério do Desenvolvimento, para saber o que o governo pretende fazer com relação a isso.

O primeiro a ser entrevistado seria o presidente da XY no Brasil. A repórter pretende conseguir os dados com a Associação Nacional dos Fabricantes de Automóveis, com o Sindicato dos Metalúrgicos e com economistas. Da associação e do sindicato ela espera obter informações sobre a conjuntura no setor, ou seja, conhecimento específico: se se trata de um caso de retração de venda no mercado interno de automóveis ou de redução de importaçőes, se é uma questão sazonal ou estrutural, que levaria mais tempo para ser solucionada. A própria jornalista justifica a escolha dessas fontes parciais como experts quando afirma que, hoje em dia, esses sindicatos são muito bem aparelhados em termos de análises setoriais, também. Por que essa repórter entrevistaria ainda economistas? 
De um lado, nós temos o setor automotivo. Do outro lado, o sindicato, que é um elemento envolvido diretamente na produção. Os economistas eu ouviria porque são elementos que não estariam diretamente envolvidos naquele setor. Poderiam falar com a distância que têm do mesmo.

De onde vêm esses economistas? "Nós já temos aqui algumas fontes. [...] Se o economista for de uma entidade, eventualmente a gente passa por uma assessoria de imprensa, mas não necessariamente. Em vários casos, a gente já tem o telefone celular dessa pessoa. Aí o contato é mais direto", responde.

Embora os representantes a serem ouvidos na associação dos fabricantes e no sindicato sejam experts, eles não gozam do status de neutralidade, o que aponta para o fato de que o conhecimento específico não é suficiente para que a análise do informante seja considerada neutra. A sua vinculação institucional é, no mínimo, tão importante quanto a sua expertise.

Considerando-se as perguntas a serem feitas para cada tipo de expert, pode-se observar que os experts tidos como parciais responderiam a perguntas tanto no nível factual (como o número de automóveis vendidos) quanto no nível interpretativo (previsão de cenários). Já do expert considerado neutro a repórter só exige informaçőes no nível interpretativo. Ou seja, no caso dos experts considerados parciais, a repórter trabalha, pelo menos em parte, com hipóteses descritivas, enquanto que, no caso da fonte "neutra", ela espera somente avaliaçőes e prognoses, por exemplo, "se a decisão da empresa é acertada", "se, dada a saúde financeira dessa empresa, essa seria a decisão ideal dela ou se ela poderia suportar esse momento para garantir mercado interno".

O que faz de alguém um expert, além do fato de seu nome constar na caderneta de telefones da redação como tal, é uma questão que precisa ser analisada em estudos empíricos futuros. Pode-se, no entanto, reconhecer claramente a influência das rotinas produtivas 
nesse caso. A escolha de um expert como resultado de sugestões da redação pode ser observada em todas as editorias. No entanto, a maneira de escolher experts acessíveis pode variar, uma vez que os jornalistas entrevistados não seguem a regra da divisão do trabalho cognitivo. Em outras palavras, para esses repórteres, a questão não é quem produz conhecimento sobre o tema a ser investigado, mas, sim, quem poderia ser um expert dentro da área de cobertura pela qual são responsáveis. Assim sendo, o setorista do Congresso Nacional não iria procurar um pesquisador de estudos da violência, mas um deputado que faça parte da comissão de segurança pública no Parlamento.

\section{O caso especial do noticiário econômico}

Repórteres das editorias locais trabalham, primordialmente, com hipóteses descritivas (Gráfico 2). O caso de um repórter de um jornal regional permite ilustrar bem esse resultado. Ele recebeu uma história na qual a polícia anuncia um programa de combate aos assaltos em ônibus por meio de uma campanha de desarmamento nas regiőes afetadas e deseja saber se o número de assaltos a ônibus nessas regiões tem aumentado, se a polícia planeja medidas concretas a serem adotadas nas linhas de ônibus atingidas e se, nos bairros que sofrem com o problema, há opçőes de lazer para a população.

A maior parte das hipóteses formuladas por jornalistas que cobrem política é descritiva, porém, mais de um terço destas é do tipo avaliativo. Assim, um setorista que trabalha no Congresso Nacional deseja "testar" se os moradores de favelas consideram a decisão de uma intervenção do Exército no combate à criminalidade boa ou ruim, "se isso vai ajudar ou atrapalhar”. Ele quer saber de um representante da Organização dos Advogados do Brasil (OAB) "se é mesmo função do Exército combater o tráfico organizado". 
O maior percentual de hipóteses que não podem ser testadas intersubjetivamente foi observado no caso dos repórteres de economia: 28\% das hipóteses desse grupo são avaliativas e 19\%, prescritivas. Esses jornalistas formulam hipóteses prescritivas quando propõem soluçőes para os problemas sobre os quais iriam noticiar e perguntam aos seus informantes se concordam com elas. Um dos repórteres dessa área recebeu uma história sobre o fim de uma greve depois de um acordo entre os representantes da empresa e do sindicato dos trabalhadores e deseja verificar se "pagar uma PLR (Participação nos Lucros e Rendimentos) menor (do que a que o sindicato reivindicava) não é uma forma de não demitir e se existe uma perspectiva de faturar mais e passar a remunerar melhor”.

\begin{tabular}{|l|cccc|}
\hline \multirow{2}{*}{ Editoria } & \multicolumn{5}{|c|}{ Número de fontes em \% } \\
& Descritiva & Avaliativa & Prescritiva \\
\hline Economia & 54 & & 24 & 22 \\
Política & 59 & & 41 & \\
Local & & 79 & 15 & 6 \\
\hline
\end{tabular}

Gráfico 2 - Tipos de hipóteses por editoria.

No caso da editoria de economia, o problema nos critérios de escolha de experts é, portanto, potencializado por outra característica desse tipo de cobertura, a concentração em hipóteses que não podem ser testadas intersubjetivamente. A falta de averiguação das declaraçőes de experts com uma segunda fonte adquire uma dimensão própria, não só porque experts são procurados, sobretudo, nessa editoria, mas também porque grande parte das hipóteses com as quais jornalistas econômicos trabalham não pode ser avaliada segundo a escala certo/errado. Para que o método de investigação desses repórteres possa contribuir, de fato, para evitar uma percepção 
equivocada, é imprescindível procurar uma aproximação da realidade mediante a busca de mais de uma explicação.

Além disso, diferentemente do que acontece na editoria de política, não há uma definição clara de quem defende qual posição nos temas de economia. No noticiário político, é possível que um expert, com o seu status de "fonte neutra", fortaleça um dos lados da polêmica. No entanto, como os jornalistas entrevistados ouviriam os dois lados, o lado desprivilegiado continua tendo possibilidade de apresentar seu ponto de vista. No caso da cobertura econômica, não há uma “oposição” que possa representar “o outro lado”. A discussão sobre a plausibilidade de uma explicação ou uma prognose precisa ser garantida de outra forma.

Para alcançar o que os repórteres de política alcançam com o princípio de fairness, é preciso que jornalistas econômicos escolham experts que tenham visões diferentes sobre um mesmo problema. Visto que os repórteres entrevistados tendem a ignorar experts como defensores de uma opinião e procuram sempre os mesmos, eles desperdiçam a oportunidade de utilizar a expertise de suas fontes para se aproximar mais da realidade. Isso ocorre por um déficit de iniciativa própria de investigar, de averiguar as informaçőes, e pode gerar um problema de transparência, já que uma fonte parcial - como no caso de think tanks - passa a ser classificada como neutra.

\section{Discussão}

Analisando-se a literatura sobre o tema, percebe-se que, no processo deprodução jornalística, o termo expertrecebeuma definição diferente da utilizada na perspectiva sociológica. Conhecimento específico não basta. A acessibilidade e a qualidade comunicativa têm, no mínimo, a mesma importância. O levantamento empírico aqui apresentado mostra, ainda, que essa acessibilidade tem outro 
componente, o de que a escolha dos experts acessíveis está ligada à lógica que rege a área de cobertura do jornalista. Conhecimento específico pode servir para "neutralizar" uma fonte. Como tais informantes são considerados neutros, torna-se desnecessário confrontá-los com outros e as interpretaçőes que oferecem passam a ser naturais.

Neste estudo, entretanto, observou-se que nem todo expert é considerado neutro. A sua "neutralidade" depende tanto da sua expertise quanto da sua vinculação institucional. Os resultados empíricos também mostram que tratar um expert como uma fonte parcial faz grande diferença na investigação jornalística, já que somente as informações de fontes consideradas como tais são averiguadas com outro informante.

Levando-se em conta a "neutralidade" do conhecimento específico na maior parte dos casos observados, pode-se dizer que as rotinas de produção jornalística geram condições extremamente favoráveis para que fontes parciais apresentem suas opiniões sem concorrência.

Think tanks podem e devem ter a possibilidade de apresentar seus pontos de vista em sociedades democráticas pluralistas, da mesma forma que é obrigação do jornalista questionar o teor de realidade de suas declaraçőes. Isso significa que não só a reação de jornalistas às iniciativas de fontes ativas como think tanks deve ser questionada, mas também, de maneira geral, a forma como esses profissionais lidam com os limites da expertise.

Explicaçőes de experts devem ser tratadas como hipóteses, não como certeza absoluta. Expertise, ainda que tenha um fundamento científico, não pode espelhar a realidade (Popper, 1984). Por outro lado, embora o conhecimento científico consista em hipóteses, a obrigação dos jornalistas de fornecer uma representação adequada da realidade exige que eles separem opiniőes e meras conjecturas de suposiçőes científicas (Schneckener, 2005, p. 9). 
Conhecimento científico se caracteriza por uma observação controlada da realidade, que precisa seguir uma série de regras, entre elas, a da intersubjetividade, visando garantir a transparência do método utilizado (Atteslander, 1995, p. 15; Popper, 1994, p. 18). Opiniőes e conjecturas não precisam nem resultar de observação controlada, nem ser intersubjetivas (Stocking, 1990). Isso significa, concretamente, que estudos de tais organizaçőes devem ser questionados criticamente: qual foi a amostra utilizada? Como e por que ela foi escolhida? Qual o método utilizado? Os resultados obtidos permitem ao estudioso chegar a tais conclusőes?

Não somente no caso da divulgação de estudos, mas, de maneira geral, é preciso localizar a posição do expert em um contexto maior e apresentá-la como uma entre outras. Para isso, é imprescindível questionar quem é esse expert, quais são as suas ligações institucionais e os valores defendidos por essa organização. Por último, jornalistas deveriam refletir por que experts devem escapar do princípio de fairness ("ouvir os dois lados") (Lage, 2001).

Além dos limites das redações, também se deve considerar a responsabilidade social de cientistas e acadêmicos nesse contexto. Com um entendimento mais profundo do público (scientist understanding of public) e uma capacidade comunicativa maior, sua contribuição para resolver esse problema poderia ser de grande relevância.

\section{Notas}

1 Um dos exemplos desse reconhecimento foi o prêmio recebido da Fundação Bill e Melinda Gates em 2003. Ver a respeito: Bill and Melinda Gates Foundation (2003).

2 Os dados fazem parte da tese de doutorado da autora, na qual os métodos de investigação dos repórteres são analisados teórica e empiricamente 
segundo critérios crítico-racionalistas de objetividade. Neste artigo, serão apresentados somente os resultados relacionados às fontes do tipo expert.

3 Setoristas (equivalentes aos beat reporters no contexto norte-americano) são repórteres que têm uma área tanto temática quanto geográfica fixa para realizar sua cobertura jornalística. O caso mais comum é o dos correspondentes parlamentares.

4 Correlação entre tipo de fonte e editoria: Cramer-V $=0,324, p=$ 0,016 .

5 Correlação entre critério de escolha da fonte e tipo de fonte: Cramer-V $=0,488, \mathrm{p}=0,001$.

Neutralising knowledge: how journalists deal with experts

Abstract: Journalists are a favored target for influencing political and economic events in society. They are the targets not only of parties and politicians, but also of think tanks and their experts. How prepared are journalists to react both critically and productively to such initiatives? A qualitative survey of reporters from local and national newspapers shows how experts on disputed topics are selected, which information journalists expect from these informants and how journalists view these sources. The results demonstrate that the surveyed journalists routinely select the same experts and do not cross-examine the information gathered.

Key words: think tanks; experts; knowledge; journalism.

\section{Referências}

ATTESLANDER, Peter. Methoden der empirischen Sozialforschung. Berlin: de Gruyter, 1995.

BAERNS, Barbara. Öffentlichkeitsarbeit oder Journalismus: Zum Einfluss im Mediensystem. Köln: Wissenschaft und Politik, 1985. 
BBC 2005. "Brasil ameaça pesquisa sobre AIDS, diz instituto”. Disponível em: <http://www.bbc.co.uk/portuguese/reporterbbc/story/2005/12/ printable/051216_aidsprogramme.shtml $>$. Acesso em: 22 maio 2008.

BILL AND MELINDA GATES FOUNDATION. Brazilian National AIDS Program Receives 2003 Gates Award for Global Health. Disponível em: <http://www.gatesfoundation.org/GlobalHealth/ Announcements/Announce-030528.htm>. Acesso em: 22 maio 2008.

BOHMAN, James. The division of labor in democratic discourse: media, experts, and deliberative democracy. In: CHAMBER, Simone; COSTAIN, Anne (Orgs.). Deliberation, democracy and the media. Lanham: Rowman and Littlefield, 2000, p. 47-64.

BOYCE, Tammy. Journalism and expertise. Journalism Studies, v. 7, n. 6, p. 889-906, 2006.

CONRAD, Peter. Uses of expertise: sources, quotes, and voice in the reporting of genetics in the news. Public Understanding of Science, v. 8, n. 4, p. 285-302, 1999.

DOLNY, Michel. Think tanks in a time of crisis. Fair's 2001 survey of the media's institutional experts. Extra!, p. 28-29, Mar./Apr. 2002.

DUNWOODY, Sharon; RYAN, Michael. The credible scientific source. Journalism Quarterly, v. 64, n. 1, p. 21-27, 1987.

; SCOTT, Byron T. Scientists as mass media sources. Journalism Quarterly, v. 59, n. 1, p. 52-59, 1982.

GANS, Herbert J. Deciding what's news. New York: Pantheon, 1979.

GENRO FILHO, Adelmo. O segredo da pirâmide: por uma teoria marxista do jornalismo. Porto Alegre: Tchê, 1988.

HALLER, Michael. Recherchieren: Ein Handbuch für Journalisten. 5. ed. München: Ölschlager Verlag, 2000.

HESSE, Hans Albrecht. Experte, Laie, Dilettant: über Nutzen und Grenzen von Fachwissen. Wiesbaden: Westdeutcher Verlag, 1998. 
LAGE, Nilson. A reportagem: teoria e técnica de entrevista e pesquisa jornalística. São Paulo: Record, 2001. . Ideologia e técnica da notícia. Petrópolis: Vozes, 1979.

McNAIR, Brian. The sociology of journalism. London: New York: Arnold and Oxford University Press, 1998.

MEDITSCH, Eduardo. O conhecimento do jornalismo. Florianópolis: Editora da UFSC, 1992.

NEUBERGER, Cristopher. Journalismus als Problembearbeitung: Objektivität und Relevanz in der öffentlichen Kommunikation. Konstanz: UVK Medien, 1996.

OMELLAS, Gisela V. C. S. "O agenciamento informativo pelas assessorias de imprensa: um estudo de caso da junção Varig e TAM" (trabalho apresentado no XVIII Congresso Brasileiro de Ciências da Comunicação), Rio de Janeiro, 5-9 set. 2005.

PARK, Robert. News as a form of knowledge. In: TURNER, Ralph H. (Org.). On social control and collective behavior. Chicago: Chicago University Press, 1967.

PEDROSO, Rosa Nívea. Considerações sobre produção, discurso e análise em jornalismo. Sala de Prensa, v. 3, ano VII, abr. 2005. Disponível em: <http://saladeprensa.org/art601.htm>. Acesso em: 22 maio 2008.

PEREIRA, Fábio H. O “jornalista sentado" e a produção da notícia online no CorreioWeb. Em Questão, v. 10, n. 1, p. 95-108, 2004.

POPPER, Karl. R. Logik der Forschung. 10. ed. Tübingen: Mohr, 1994.

. Objektive Erkenntnis. 4. ed. Hamburg: Hoffman und Campe, 1984.

RESENDE, Lino G. "Economia, valor notícia e assessorias de imprensa”. Disponível em: <http://www.bocc.ubi.pt/pag/resende-linoeconomia-valor-noticia.pdf>. Acesso em: 22 maio 2008. 
ROTHMAN, Stanley. The media, the experts, and public opinion. In: (Org.). The mass media in liberal democratic societies. New York: Paragon House Publishers, 1992.

SCHNABEL, Ulrich. God's formula and devil's contribution: science in the press. Public Understanding of Science, v. 12, n. 3, p. 255-259, 2003.

SCHMECKER, Ulrich. "Die soziale Konstruktion des 'Terrorexperten': Terrorismusforschung zwischen Medienlogik und Politikberatung” (Diskussionspapier der FG8, 2005/03, Mai 2005), Berlin: Stiftung Wissenschaft und Politik, 2005.

SIGAL, Leon. Reporters and officials: the organisation and politics of newsmaking. Lexington, MA: D. C. Heath, 1973.

. Sources make the news. In: MANOFF, R. K.; SCHUDSON, Michael (Orgs.). Reading the news. New York: Pantheon Books, 1986.

SOLEY, Lawrence. Heritage clones in the heartland. Local think tanks "research" comes pre-digested. Extra!, CIDADE, Sept./Oct. 1998. Disponível em: $<$ http://www.fair.org/index.php?page=1430>. Acesso em: 22 maio 2008.

. The newsshapers: the sources who explain the news. New York: Paeger Publishers, 1992.

SOUSA, Jorge Pedro. Uma teoria multifactorial da notícia. In: FIDALGO, António; SERRA, Paulo (Orgs.). Ciências da Comunicação em Congresso na Covilhã. CCCC. III SOPCOM. VI LUSOCOM. II IBÉRICO. v. 4. Campos da Comunicação. Covilhã: Universidade da Beira Interior/Labcom, 2005.

SPONHOLZ, Liriam. Entre senso comum e ciência: o conhecimento híbrido do jornalismo. Ciências \& Cognição, CIDADE, v. 10, p. 2-14, 2007. Disponível em: <http://www.cienciasecognicao.org>. Acesso em: 22 maio 2008. 
SPRONDEL, Walter M. "Experte" und "Laie": Zur Entwicklung von Typenbegriffen in der Wissenssoziologie. In:

GRATHOFF, Richard. Alfred Schütz und die Idee des Alltags in den Sozialwissenschaften. Stuttgart: Enke Verlag, 1979.

STEELE, Janet E. Experts and the operational bias of television news. The case of the Persian Gulf War. Journalism and Mass Communication Quarterly, v. 72, n. 3, p. 799-812, 1995.

STOCKING, Susan H.; LaMARCA, Nancy. How journalists describe their stories: hypotheses and assumptions in newsmaking. Journalism Quarterly, v. 67, n. 2, p. 295-301, 1990.

THUNERT, Martin. Conservative think tanks in the United States and Canada. In: SCHULTZE, Rainer-Olaf; STURM, Roland; EBERLE, Dagmar (Orgs.). Conservative parties and right-wing politics in North America. Opladen: Leske und Budrich, 2003.

WEISCHENBERG, Siegfried. Journalistik. Theorie und Praxis aktueller Medienkommunikation. Band I: Mediensysteme, Medienethik, Medieninstitutionen. Opladen: Westdeutscher Verlag, 1992. 